\title{
Interleukin-27 acts on hepatic stellate cells and induces signal transducer and activator of transcription 1-dependent responses
}

\author{
Caroline Schoenherr ${ }^{1}$, Ralf Weiskirchen², Serge Haan ${ }^{1,3^{*}}$
}

\begin{abstract}
Background: Interleukin (IL)-27 is a cytokine belonging to the IL-6/IL-12 cytokine family that is secreted by activated macrophages and dendritic cells and which strongly acts on T-cells and cells of the innate immune system. Not much is known about possible effects of IL-27 on other cell types. It signals via the common IL-6-typecytokine receptor chain gp130 and the IL-27-specific chain WSX-1. We previously described that IL-27 also stimulates hepatoma cells and primary hepatocytes. The aim of this study was to investigate whether IL-27 would also act on hepatic stellate cells (HSC), the second most abundant hepatic cell type, which would demonstrate a more general role of this cytokine in the liver.

Results: Using a human HSC line and primary rat HSC we investigated the signalling characteristics of IL-27 in these cells. We show that IL-27 activates signal transducer and activator of transcription (STAT) 1 and to a minor extent STAT3 in a human HSC cell line and that it leads to the induction of STAT1 target genes such as interferon response factor-1, myxovirus resistance A and STAT1 itself. Similarly we find that IL-27 also elicits STAT1-dependent responses in primary rat HSC.

Conclusions: We provide the first evidence for a function of IL-27 in HSC and show that its responses resemble Interferon- $\gamma$-like functions in these cells. Our data suggests that IL-27 may play an important role in the context of liver inflammation by acting on the different liver cell types.
\end{abstract}

\section{Background}

Liver inflammation is most often induced by viral infections, alcohol, drugs or chemical intoxication. Generally, it is associated with liver fibrosis, a wound-healing response to liver injury [1]. Among the hepatic cell types, hepatic stellate cells (HSC) are most important for this process. Activated HSC migrate and proliferate at the site of injury and perpetuate the inflammation. A key factor for the transformation of quiescent HSC into fibrogenic myofibroblasts is the cytokine transforming growth factor- $\beta$ (TGF- $\beta$ ) [2].

Interleukin-27 (IL-27) is a type-I-cytokine belonging to the IL-6/IL-12 superfamily of cytokines [3]. It is predominantly secreted by activated macrophages and dendritic cells. As the other IL-12 family members, IL-12 and

\footnotetext{
* Correspondence: serge.haan@uni.lu

'Department of Biochemistry, University Hospital RWTH-Aachen,

Pauwelsstrasse 30, D-52074 Aachen, Germany

Full list of author information is available at the end of the article
}

IL-23, IL-27 has profound effects on T-cells and acts on innate immune cells $[4,5]$. Most studies investigated the effects of IL-27 on CD4+ T-cells but not much is known about possible effects of IL-27 on other cell types. IL-27 signals via a receptor complex composed of the IL-27-specific receptor chain WSX-1 [3] and the common receptor subunit of IL-6-type cytokines, gp130 [6]. It is thus also a member of the IL-6-type cytokine family. We previously reported a function of IL-27 in hepatoma cells and primary hepatocytes and showed that IL-27 responses are not restricted to the classical immune cells. IL-27 was shown to exert Interferon- $\gamma-$ like functions in hepatocytes/hepatoma cells and to contribute to the antiviral response in these cells [7]. The potential importance of this finding is highlighted by a recent study showing that Hepatitis B virus (HBV) enhances IL-27 expression in vivo and in vitro [8].

In the present study, we describe for the first time that IL-27 acts on hepatic stellate cells and elicits an efficient 
Signal transducer and activator of transcription (STAT)1 response in these cells.

\section{Results}

IL-27 induces STAT1 and STAT3 phosphorylation in a human hepatic stellate cell line

Using the human LX-2 cell line, we first assessed whether these cells express both IL-27 receptor chains. This cell line retains key features of primary HSC and the gene expression profile shows strong similarities to those of primary cells (98.7\%) [9]. As shown in the FACS-analysis in figure 1, we observed that both IL-27 receptor chains, gp130 and WSX-1, are expressed on these cells. Next, the cells were treated with IL-27 for up to 12 hours and tyrosine phosphorylation of STAT3 (pY705) and STAT1 (pY701) was assessed by Western blot analysis. As a control, the cells were stimulated with IFN $\gamma$ or with Interleukin-6 (IL-6) together with its soluble receptor, sIL- $\alpha$. IL-27 induces a sustained phosphorylation of STAT1 and STAT3 (figure 2A). As expected, IFN $\gamma$ induced mainly STAT1 phosphorylation whereas IL-6 initiated a rapid and pronounced STAT3 phosphorylation. The kinetics of STAT1 and STAT3 activation by IL-27 were comparable but peaked at later time points if compared to the phosphorylation kinetics obtained after IL- 6 stimulation. As previously observed IL-6 leads to a weak and transient phosphorylation of STAT1 $(10,20$ and 30 min time points in figure 2A) [10]. This underlines that STAT1 phosphorylation itself is not a good indicator for the formation of active STAT1 homodimers, especially if only early time points are considered. For example, upon treatment of hepatoma cells and primary human macrophages with IL-6-type cytokines (e.g. IL-6 or OncostatinM) STAT1 phosphorylation can be observed but most of the phosphorylated
STAT1 is rather trapped in STAT1/STAT3 heterodimeric complexes [10]. We thus performed electrophoretic mobility shift assays (EMSA) to examine whether phosphorylated STAT1 is forming homodimers upon treatment of LX-2 cells with IL-27 (figure 2B). As controls we used cells stimulated with IL-6/ sIL- $\alpha$ or IFN $\gamma$. The sustained formation of STAT1/ STAT1 complexes shows that IL-27 induces a persistent STAT1 activation in these cells.

\section{IL-27 mediates STAT1-dependent responses in human hepatic stellate cells}

As IL-27 only led to a weak STAT3 phosphorylation and DNA-binding (figure 2), we monitored the induction of the STAT3-dependent feedback regulator suppressor of cytokine signalling (SOCS)-3 upon stimulation of LX-2 cells with IL-27 for up to $1 \mathrm{~h}$. Figure 3A demonstrates that SOCS3 mRNA was hardly upregulated by IL-27 whereas the IL- 6 control prominently induced SOCS3 expression. Longer treatments of the cells (up to $24 \mathrm{~h}$ ) with IL-27 did also not further increase SOCS3 mRNA levels (data not shown).

To assess whether IL-27 induces an efficient STAT1 response, we investigated whether IL-27 would regulate STAT1-dependent gene transcription and thereby mediate interferon-like responses. We performed Western blot analyses in LX-2 cells to monitor STAT1-dependent protein expression upon treatment of these cells with IL-27 or IFN $\gamma$. Figure 3B shows that IL-27 upregulates the STAT1-dependent genes STAT1, interferon response factor-1 (IRF-1) as well as myxovirus resistance A (MxA), which is implicated in the antiviral response after IFN-treatment of cells [11]. Although protein upregulation of these genes was stronger upon treatment with IFN $\gamma$, it can be concluded that IL-27 leads to IFNlike responses in these cells.
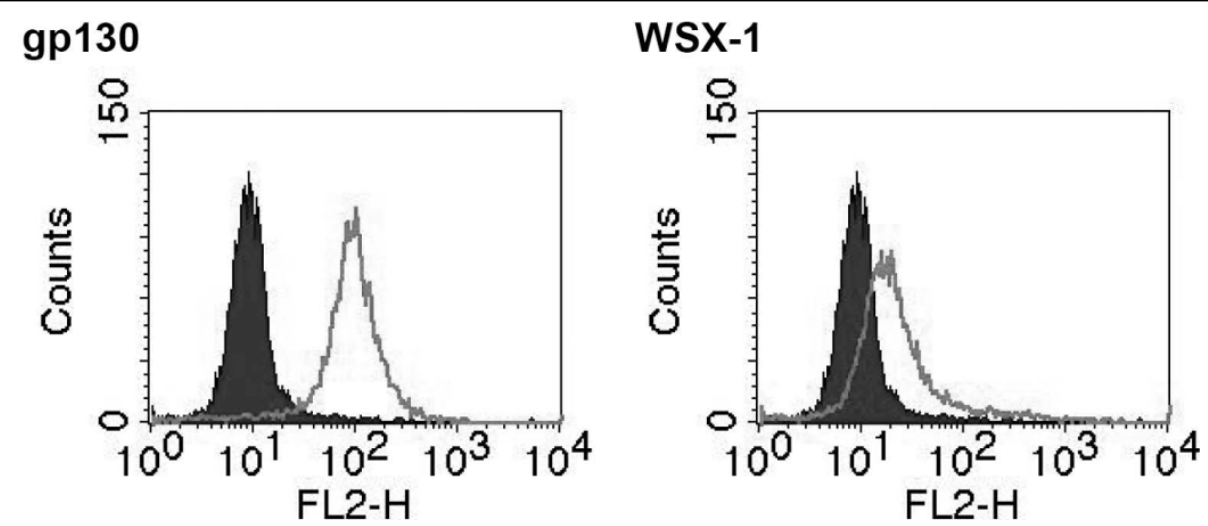

Figure 1 LX-2 cells express the IL-27 receptor chains gp130 and WSX-1. For FACS-analysis, LX-2 were incubated with a monoclonal antibody against human gp130 or human WSX-1 followed by a secondary PE-conjugated antibody. The grey histograms represent cells treated with secondary antibody only and the open histograms represent gp130 or WSX-1 surface staining. 


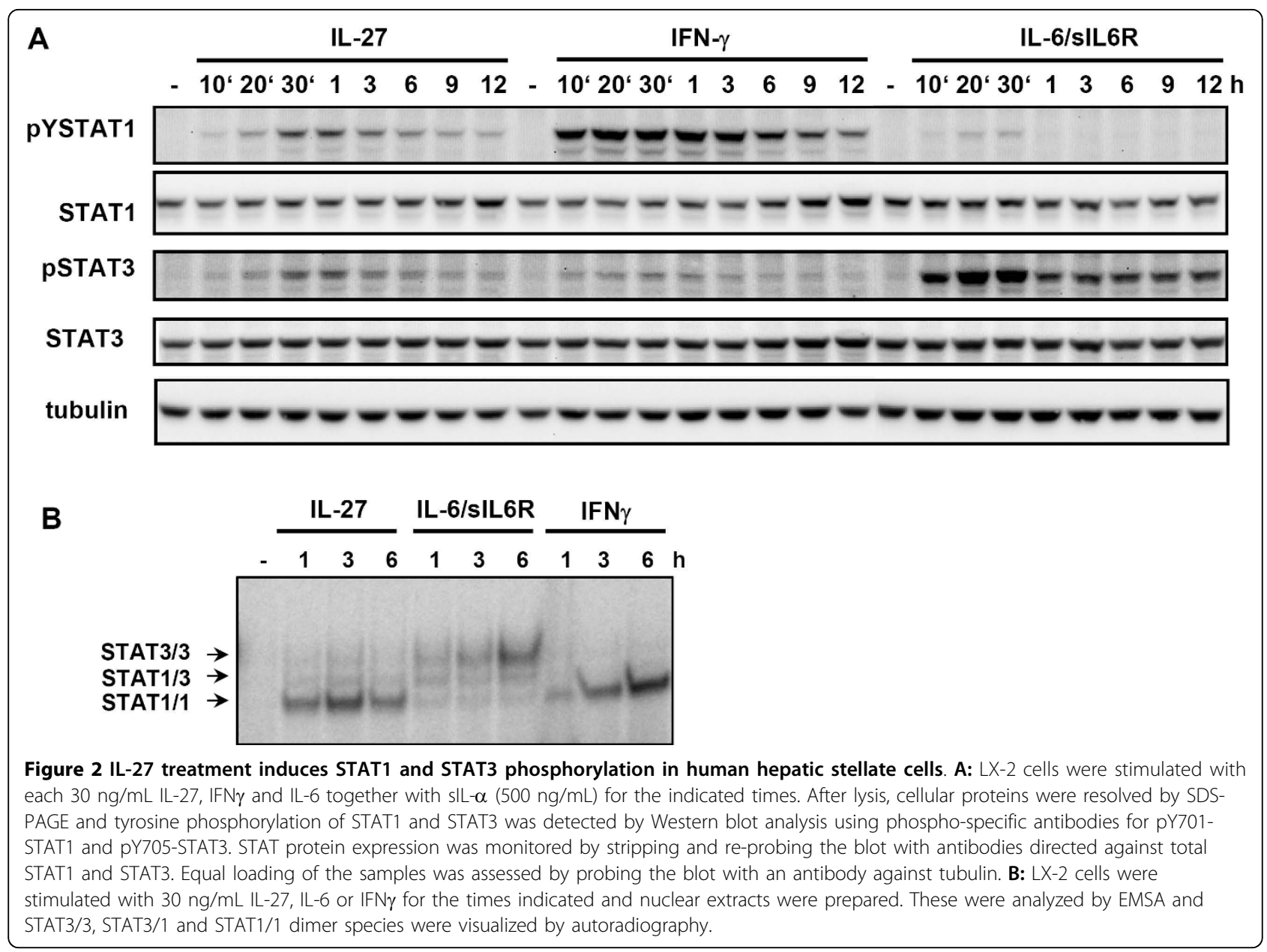

\section{IL-27 induces STAT1-dependent genes in primary rat} hepatic stellate cells

In order to test whether IL-27 also acts on HSC in primary culture we isolated rat HSC and stimulated them with IL-27 or IFN $\gamma$ for different times. As illustrated in figure $4 \mathrm{~A}$, treatment of these cells with IL-27 or IFN $\gamma$ leads to a sustained phosphorylation of STAT1. In comparison, IL-27 only leads to a weak increase in STAT3phosphorylation after 1 hour. Furthermore, as already observed in the HSC line (i.e. LX-2), IL-27 upregulates the STAT1-dependent proteins STAT1 and MxA in primary HSC and thereby induces a response resembling that of IFN $\gamma$ (figure 4B).

IL-27 stimulation does not affect the expression of Smad2 and Smad3 or the activation of a Smad-dependent reporter construct

It was recently reported that the TGF- $\alpha / \operatorname{Smad} 3$ pathway is accelerated in STAT1-deficient mice [12]. In addition, Weng et al. reported that prestimulation of rat HSC with IFN $\gamma$ for $6 \mathrm{~h}$ or $12 \mathrm{~h}$ impairs the intrinsic phosphorylation of Smad2 and Smad3 that occurs by autocrine TGF- $\beta$ stimulation [13]. Furthermore, they found Smad2 and Smad3 expression to be reduced to a comparable degree in these conditions. The effects on Smad2 were most prominent after a pretreatment of $6 \mathrm{~h}$ whereas Smad3 was most affected after a $12 \mathrm{~h}$ prestimulation [13]. We performed similar experiments to investigate whether stimulation of LX-2 cells or rat HSC with either IFN $\gamma$ or IL-27 would affect Smad2 and Smad3 expression. As shown in figure $5 \mathrm{~A}$ and $5 \mathrm{~B}$, we did not observe reduced expression of either Smad2 or Smad3 although STAT1 was clearly activated. Similarly we did not detect a clear reduction of the intrinsic Smad3 phosphorylation (figure $5 \mathrm{~B}$ ). We repeated the experiment and additionally treated the cells with TGF- $\beta$ following pretreatment with IL-27 or IFN $\gamma$ (figure $5 \mathrm{C}$ and $5 \mathrm{D})$. Similarly, we did not detect a reduction of Smad2 or Smad3 expression levels. TGF- $\beta$ stimulation slightly increased Smad3 phosphorylation (figure 5D) but prestimulation with either IL-27 or IFN $\gamma$ did not impair this activation. A reduction in Smad3 phosphorylation was always paralleled by a reduction in the loading control (tubulin detection). To further substantiate this finding, 

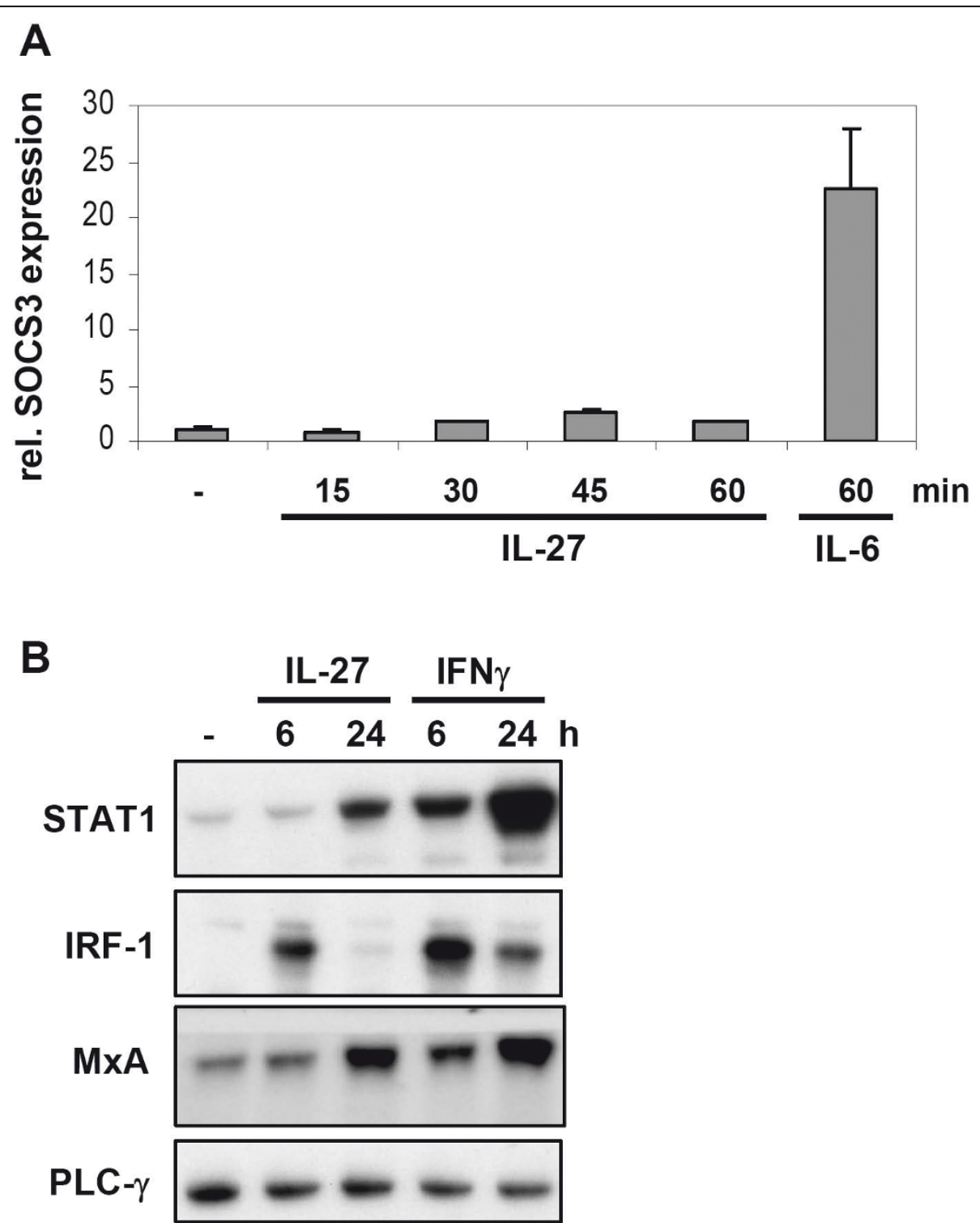

Figure 3 IL-27 mediates a STAT1 response in human LX-2 cells. A: Real-time PCR analysis of total cellular mRNA monitoring the expression of the STAT3-dependent gene SOCS3 in LX-2 cells after stimulation with IL-27 (30 ng/mL) for the times indicated. As a control, the cells were stimulated with IL-6/sIL6R (30 ng/mL/500 ng/mL) for $60 \mathrm{~min}$. Beta-actin was used as internal reference to normalize the target transcripts. Standard deviations of a triplicate experiment are given. B: Western blot analysis monitoring upregulation of the STAT1-dependent STAT1, IRF-1 and MXA protein expression upon stimulation of LX-2 cells with $30 \mathrm{ng} / \mathrm{mL} \mathrm{IL}-27$ or IFN $\gamma$ for up to $24 \mathrm{~h}$. Expression levels of PLC $\gamma$ are provided to compare the protein amount in the samples.

we performed a reporter gene analysis using a CAGAreporter construct that binds the $\mathrm{Smad} 2 / \mathrm{Smad} 3 / \mathrm{Smad} 4$ complex after phosphorylation of Smad2 and Smad3. The cells were stimulated with TGF- $\beta 1$ or IL-27 alone or in combination with both cytokines. We observed an increase in luciferase activity upon treatment of the cells with TGF- $\beta 1$ for 2 or 16 hrs but this induction was not inhibited by IL-27 co-stimulation (figure 5E). Taken together, we could not confirm inhibitory effects of IFN $\gamma$ prestimulation on Smad2 and Smad3 expression or Smad3 phosphorylation. Similarly, pretreatment with IL-27 did not affect these parameters.

\section{Discussion}

Interleukin-27 was previously described to be involved in inflammatory processes within the gastrointestinal tract. It was shown to play a key role in the context of Con-A-induced hepatitis [14], Crohn's Disease [15] as well as in the initiation and progression of colon carcinoma $[16,17]$. Furthermore, IL-27 was recently reported 


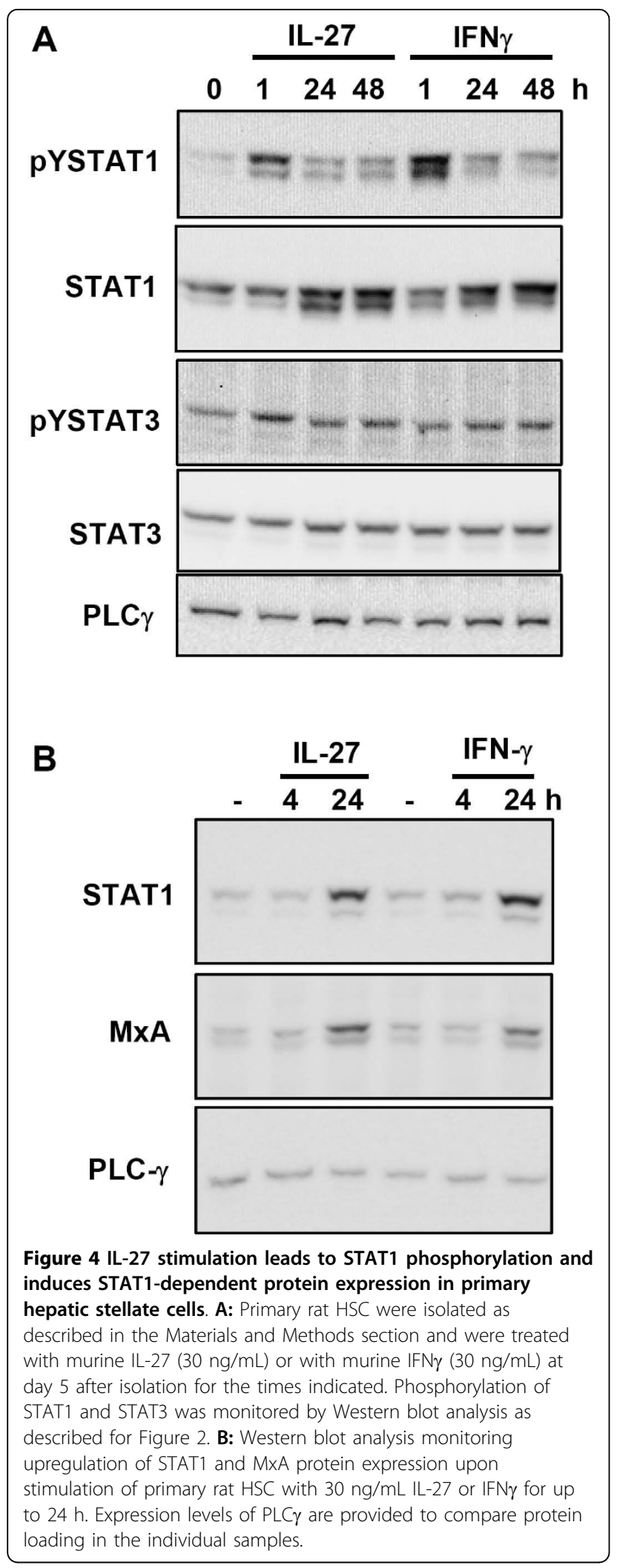

to possess strong antitumor activity in a murine model of hepatocellular carcinoma [18]. These studies highlight the importance of IL-27 expression in the gastrointestinal tract and the liver. However, the reported functions of IL-27 were all restricted to infiltrating immune cells such as T-cells and natural killer cells. Recently, we reported a first function for IL-27 on a hepatic cell type, namely hepatocytes [7]. Here we investigated whether the second most abundant liver cell type (i.e. HSC) also responds to IL-27. We show that IL-27 induces a STAT1 response in these cells and upregulates proteins involved in antiviral responses.

The members of the IL-6 type family of cytokines play important roles in the liver as they contribute to the acute-phase response of the liver as well as liver regeneration [19-21]. These functions of IL-6-type cytokines are largely dependent on the activation of the transcription factor STAT3 and the formation of activated STAT3/STAT3 dimers. The activation of STAT3 is mediated via the IL-6-type cytokine receptor chains gp130, oncostatinM receptor and leukemia inhibitory factor receptor [6]. Although these receptors can also recruit STAT1 and lead to its phosphorylation, IL-6type cytokines such as IL-6 and OSM fail to induce an efficient STAT1 response in cell types such as hepatocytes and macrophages $[10,22,23]$. It was reported that the majority of the phosphorylated STAT1 is trapped in STAT1/STAT3 heterodimers [10]. This provides an explanation for the fact that IL-6 and OSM induce an interferon-like response in STAT3 knock-out cells $[22,23]$. In this case, the lack of STAT3 prevents the formation of heterodimers and will thereby lead to the formation of STAT1 homodimers.

IL-27 signals via a signalling complex containing the STAT3 activating receptor chain gp130 and a STAT1 activating receptor chain WSX-1 [24]. Here we report that IL-27 mediates an efficient STAT1 response in HSC (figures 3B and 4). Furthermore, we only found a weak induction of a STAT3-dependent gene, SOCS3 (figure 3A). In classical immune cells such as CD4+ T cells and macrophages, the importance of STAT1 for the various biological activities of IL-27 was shown [25-27]. However, it was also reported that IL-27 activates both STAT1 and STAT3 in early activated T-cells whereas it displays a preferential activation of STAT3 in fully activated CD4+ T cells [28]. This suggests that specific IL-27 responses may be the result of differently regulated STAT1 and STAT3 responses and that the extent of STAT3 activation (via gp130) and STAT1 activation (via WSX-1) may depend on the cell type and/or on the activation status of the cell. Such a preference 
A

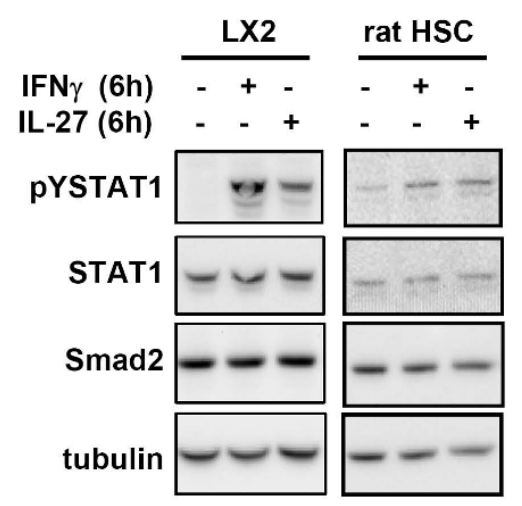

C

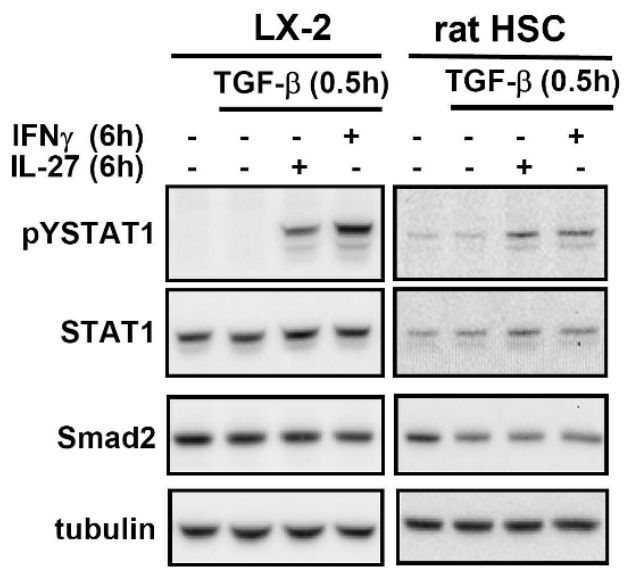

B

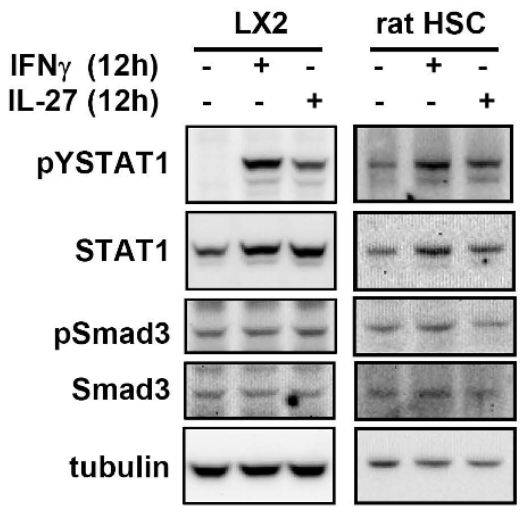

D

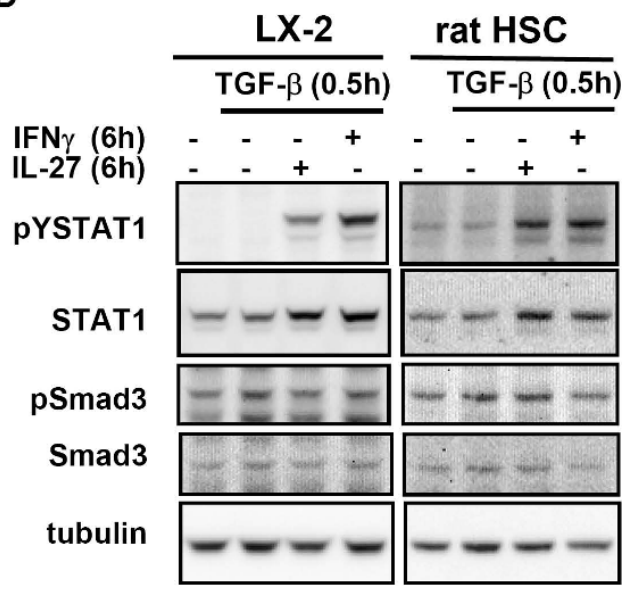

E

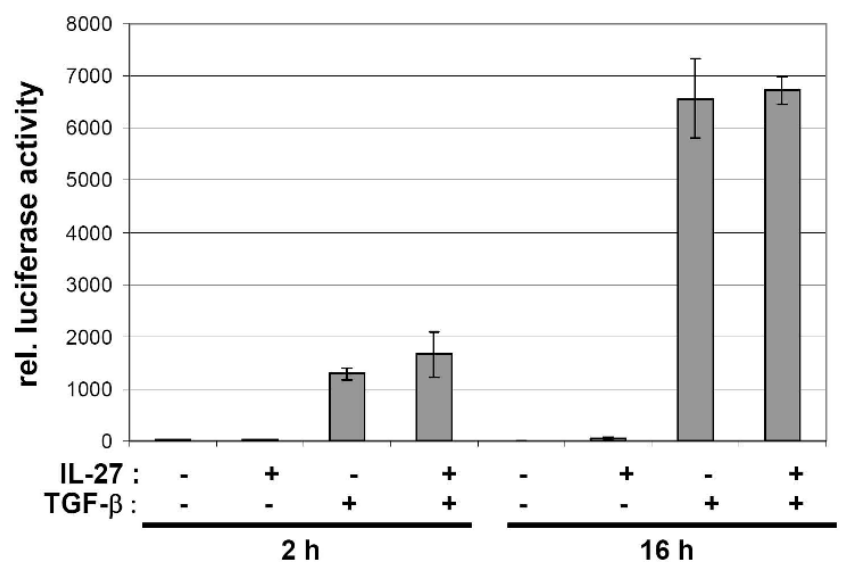

Figure 5 IL-27 stimulation does not affect TGF- $\beta$-mediated activation of Smad proteins in LX2 cells and rat HSC. A, B: LX-2 cells or rat HSC were pretreated with IL-27 (30 ng/mL) or IFN $\gamma(30 \mathrm{ng} / \mathrm{mL})$ for $6 \mathrm{~h}(\mathbf{A})$ or $12 \mathrm{~h}(\mathbf{B})$. Expression of Smad2 (A) or phosphorylation and expression of Smad3 (B) was monitored by Western blot analysis. Staining for tubulin, pY-STAT1 and STAT1 are provided as controls. C, D: LX-2 cells or rat HSC were pretreated with IL-27 (30 ng/mL) or IFN $\gamma(30 \mathrm{ng} / \mathrm{mL})$ for $6 \mathrm{~h}(\mathbf{C})$ or $12 \mathrm{~h}$ (D) and were subsequently stimulated with TGF- $\beta$ $(1 \mathrm{ng} / \mathrm{mL}$ ) for $0.5 \mathrm{~h}$. Expression of Smad2 (C) or phosphorylation and expression of Smad3 (D) was monitored by Western blot analysis. Staining for tubulin, PY-STAT1 and STAT1 are provided as controls. E: Induction of a Smad2/Smad3/Smad4-dependent CAGA reporter construct after treatment of LX-2 cells with IL-27 (30 ng/mL), TGF- $\beta$ ( $1 \mathrm{ng} / \mathrm{mL})$ or both for $2 \mathrm{~h}$ or $16 \mathrm{~h}$. Standard deviations for a triplicate experiment are given as error bars. 
for STAT1 or STAT3 responses could solely be due to different STAT expression levels (and thus a different distribution of STAT-dimer species), differences in Janus kinase activation by specific receptor chains or it could for example depend on the involvement of specific regulatory proteins. As we consistently observe a much lower STAT3 activation by IL-27 in hepatocytes and hepatic stellate cells compared to IL- 6 one can also speculate that the STAT3 activation after IL-27 stimulation does not reach a necessary threshold for efficient induction of STAT3-dependend genes such as SOCS3. Also, the delayed kinetics of STAT3 phosphorylation if compared to IL-6 may contribute this effect (figure 2A). It must be noted however that in HSC SOCS3 upregulation was also not apparent at later time points following IL-27 stimulation (data not shown). Our present data fits to our previous observation that IL-27 does not regulate the STAT3-dependent acute-phase proteins $\gamma$-fibrinogen and hepcidin in hepatocytes and hepatoma cells [7]. The data suggest that the STAT1 response is the most important feature in IL-27 stimulated liver cells. The sustained and efficient STAT1 response upon stimulation of cells with IL-27 is mediated via the WSX-1 chain of the receptor complex [24]. WSX-1 contains a single conserved tyrosine motif $\left(\mathrm{Y}_{609} \mathrm{EKHF}\right)$ which resembles the STAT1-recruiting motif of the Interferongamma receptor $1\left(\mathrm{Y}_{440} \mathrm{DKPH}\right)[29]$. Interestingly, this motif clearly differs from the tyrosine motifs of gp130 that are reported to recruit STAT1 (Y905 LPQ, $\left.\mathrm{Y}_{915} \mathrm{MPQ}\right)$ [30]. As these motifs $\left(\mathrm{Y}_{905}\right.$ and $\left.\mathrm{Y}_{915}\right)$ are also the motifs that bind STAT3 with the highest affinity [31] it is conceivable that the competition between STAT1 and STAT3 at these motifs is responsible for the inefficient STAT1 activation via the gp130 chain and/or the preferred formation of STAT1/STAT3 homodimers [10].

It was reported that IL-27 can have antiviral activities in PBMCs, CD4+ T cells and macrophages and that it can inhibit HIV-1 replication [27,32]. It can induce IFNinducible antiviral genes such as myxovirus protein 1 , 2 '-5'-oligoadenylate synthetase 2 and RNA-dependent protein kinase in macrophages, suggesting that IL-27 inhibits HIV-replication by eliciting an interferon-like response [27]. Similarly, IL-27 has antiviral activity in hepatoma cells and can induce the expression of IRF-1, guanylate binding protein 2 and MxA proteins that are involved in the antiviral response [7]. Importantly, it was recently reported that patients suffering from a hepatitis B infection have elevated IL-27 serum levels. Furthermore, IL-27 levels were also enhanced in patients with liver cirrhosis or hepatocellular carcinoma [8]. Here we show that IL-27 upregulates the STAT1-dependent genes STAT1, IRF-1 and MxA in HSC and that it initiates an IFN-like response in these cells. Our data indicate that IL-27 has wide-spread activities in the liver as it induces genes involved in host resistance to pathogens in the two most prominent hepatic cell types. IL27 may thus be a suitable candidate for studies on combination therapies against hepatitis $\mathrm{C}$, especially in light of the fact that novel IFN-based products are currently being developed [33].

The potential importance of our observations for liver inflammation is further supported by a recent report which provides evidence that liver dendritic cells produce high amounts of IL-27 instead of IL-12 upon endotoxin exposure [34]. In this experimental setting, the secreted IL-27 would of course affect responding liver cells such as hepatocytes and HSC.

STAT1 is discussed to be a negative regulator in liver fibrosis and its activation was reported to inhibit signalling by TGF- $\beta$, one of the major players involved in liver fibrosis $[12,13]$. This cytokine is a key mediator of fibrogenesis because of its ability to induce the transition of HSC to contractile myofibroblasts and to initiate the production of extracellular matrix proteins [2]. We thus investigated whether IL-27 stimulation of HSC would inhibit TGF- $\beta / \mathrm{Smad} 2 / \mathrm{Smad} 3$ signalling. Such an effect would be of great interest because many antifibrotic drugs aim at the inhibition of HSC activation and proliferation [1]. As reported by others [13], we investigated whether prestimulation with IFN $\gamma$ would reduce Smad2 and Smad3 expression. Additionally, we also studied the effects of IL-27 prestimulation on LX-2 cells and rat HSC. However, an inhibitory effect of either pretreatment on TGF- $\beta$-mediated Smad2 and Smad3 expression was not apparent in our experiments (figure $5 \mathrm{~A}, \mathrm{~B}, \mathrm{C}$ and $5 \mathrm{D})$. Nevertheless, it must be noted that the STAT1-dependent effects on TGF- $\beta$ mediated fibrotic responses may be multifaceted and occur at various levels. For example, Ghosh et al. proposed that IFN $\gamma$ activated STAT1 inhibits Smad3 activity by competing for the interaction with the transcriptional coactivators CBP and p300 [35]. In addition, IFN $\gamma$ has also been shown to induce the Smad7, a negative regulator of TGF- $\beta$ signalling [13]. Further detailed studies will be necessary to clarify whether IL-27 can counteract the profibrotic effects of TGF- $\beta$.

\section{Conclusion}

Taken together, we show for the first time that IL-27 acts on hepatic stellate cells and that it regulates STAT1-dependent genes in this hepatic cell type. Together with our observation that IL-27 also acts on hepatocytes, a general role for this cytokine in the liver becomes obvious. We show that the liver cells can contribute to antiviral and inflammatory responses via an 
IL-27-induced STAT1 activation. Further studies will have to deal with the complex interplay between the various IL-27 responsive inflammatory cells (e.g. dendritic cells, T-cells) and the liver cells in order to dissect the precise role of IL-27 in liver inflammation.

\section{Methods}

\section{Cell culture}

Human HSC line LX-2 (kind gift of Scott L. Friedman) was maintained in DMEM/Nut.MixF-12 medium with Glutamax supplemented with $2 \%$ FBS, $100 \mathrm{mg} / \mathrm{L}$ streptomycin, and $60 \mathrm{mg} / \mathrm{L}$ penicillin. All human and murine cytokines used in this study were obtained from R\&D Systems. For cross-talk experiments, the cells were starved for $12 \mathrm{~h}$ and then prestimulated with IFN $\gamma$ or IL-27 for $6 \mathrm{~h}$ or $12 \mathrm{~h}$. Subsequently, the cells were stimulated with TGF- $\beta$ for $30 \mathrm{~min}$.

\section{Isolation and cultivation of rat hepatic stellate cells}

Rat hepatic stellate cells were isolated following a protocol that is based on enzymatic collagenase and pronase digestion of the liver followed by centrifugation of the crude cell suspension through a Nycodenz gradient. Details about the purification, seeding, culturing and estimation of purity were described previously [36]. This two-step protocol yields routinely in approximately $3-5 \times 10^{7}$ cells per rat. Experiments were performed at day 5 after isolation. All experiments were approved by the Landesamt für Natur, Umwelt und Verbraucherschutz NRW (LANUV), Recklinghausen (AZ 8.8750.10.45.08.206).

\section{Reporter gene analysis}

Reporter gene analysis was performed as previously described [7]. The pGL3-(CAGA) 12 -luc construct (kind gift of P. ten Dijke) contains a repeat of 12 CAGA elements that mediate Smad-binding [37]. TGF- $\beta 1$ stimulation experiments in LX-2 and rat HSC cells were done with a concentration of $1 \mathrm{ng} / \mathrm{ml}$ recombinant human TGF- $\beta 1$ for indicated time intervals.

\section{Cell lysis, Western blot analysis and antibodies}

Cells lysis and Western blot analysis were performed as described previously [38]. The following antibodies were used: anti-STAT3, anti-STAT1 (\#610190, \#610116, Transduction Laboratories), anti-pYSTAT3, anti-pYSTAT1, anti-PLC $\gamma$, anti-phospho-Smad3 (Ser423/425), anti-Smad3, anti-Smad2 (\#9131, \#9171, \#2822, \#9520, \#951, \#3103, Cell Signalling), anti-IRF-1, anti-MxA (sc-497, sc-50509, Santa Cruz Biotechnologies), and anti-tubulin (Sigma). HRP-conjugated secondary antibodies were purchased from DAKO. Signals were detected using the ECL system (Amersham Pharmacia Biotech).

\section{Detergent-free preparation of nuclear extracts and Electrophoretic Mobility Shift Assay (EMSA)}

The preparation of nuclear extracts and the EMSA were essentially performed as previously described [10]. Protein concentrations of nuclear extracts were measured using a NanoDrop spectrophotometer (PEQLAB). The DNA-bound STAT complexes were visualized using a Typhoon phosphorimager (Amersham Pharmacia).

\section{Real time PCR analysis}

Total mRNA was isolated with the RNeasy Kit (Qiagen) according to the manufacturer's instructions. The purified RNA was reverse transcribed with the Omniscript RT Kit (Qiagen) using random hexamer primers. Realtime PCR was carried out on an ABI PRISM 7000 Sequence Detection System (Applied Biosystems) using the following primers: $\beta$-actin: sense $5^{\prime}$-CCC TGA GGC ACT CTT CCA G-3', antisense 5'-TGC CAC AGG ACT CCA TGC CC-3'; SOCS3: sense 5'-CAC CTG GAC TCC TAT GAG AAA GTC A-3', antisense 5'GGG GCA TCG TAC TGG TCC AGG AA-3'. The relative differences between the cytokine-stimulated and control samples were calculated with the mathematical Pfaffl model established for relative quantification in real-time RT-PCR [39].

\section{Flow cytometry}

$5 \times 10^{5}$ to $1 \times 10^{6}$ cells were harvested in cold PBS supplemented with $10 \mathrm{mM}$ EDTA and $0.1 \%$ sodium azide. They were then resuspended in $100 \mu \mathrm{l}$ PBS/azide (PBS, $5 \%$ FBS, $0.1 \%$ sodium azide) and incubated with $1 \mu \mathrm{g} / \mathrm{ml}$ of monoclonal anti-human TCCR/WSX-1 (R\&D Systems) for $30 \mathrm{~min}$ at $4^{\circ} \mathrm{C}$. Cells were then washed with cold PBS azide. To visualize the bound antibodies, the cells were subsequently incubated in darkness with a $1 /$ 100 dilution of a R-phycoerythrin-conjugated antimouse IgG-Fab (Dianova, Hamburg) for $30 \mathrm{~min}$ at $4^{\circ} \mathrm{C}$. Cells were again washed with cold PBS-azide and then $10^{4}$ cells per sample were analyzed by flow cytometry using a FACSCalibur flow cytometer (Beckton Dickinson) equipped with a $488 \mathrm{~nm}$ argon laser.

\section{Acknowledgements}

This work was supported by the Deutsche Forschungsgemeinschaft DFG (SFB542-TPB11 and SFB542-TPA9). The authors are grateful to Peter ten Dijke (Department of Molecular Cell Biology and Centre for Biomedical Genetics, Leiden, The Netherlands) for kindly providing reporter vector pGL3-(CAGA) ${ }_{12}$ luc, and to Scott L. Friedman (Division of Liver Diseases, Mount Sinai School of Medicine, NY, USA) for sending cell line LX-2.

\section{Author details}

${ }^{1}$ Department of Biochemistry, University Hospital RWTH-Aachen, Pauwelsstrasse 30, D-52074 Aachen, Germany. ${ }^{2}$ Institute of Clinical Chemistry and Pathobiochemistry, University Hospital RWTH-Aachen, Pauwelsstrasse 30, D-52074 Aachen, Germany. ${ }^{3}$ Life Sciences Research Unit, University of Luxembourg, 162A Avenue de la Faïencerie, L-1511 Luxembourg, Luxembourg. 


\section{Authors' contributions}

CS performed experiments in LX2 cells and primary rat hepatocytes and helped to draft the manuscript. RW participated in the design of the study isolated and cultivated rat hepatic stellate cells and helped to draft the manuscript. SH conceived the study, performed experiments in primary rat HSC and LX2 calls and drafted the manuscript. All authors read and approved the manuscript.

\section{Competing interests}

The authors declare that they have no competing interests.

Received: 14 June 2010 Accepted: 19 August 2010

Published: 19 August 2010

\section{References}

1. Bataller R, Brenner DA: Liver fibrosis. J Clin Invest 2005, 115:209-218.

2. Gressner AM, Weiskirchen R: Modern pathogenetic concepts of liver fibrosis suggest stellate cells and TGF-beta as major players and therapeutic targets. J Cell Mol Med 2006, 10:76-99.

3. Pflanz S, Timans JC, Cheung J, Rosales R, Kanzler H, Gilbert J, Hibbert L, Churakova T, Travis M, Vaisberg E, et al: IL-27, a heterodimeric cytokine composed of EB13 and p28 protein, induces proliferation of naive CD4 (+) T cells. Immunity 2002, 16:779-790.

4. Batten $\mathrm{M}$, Ghilardi $\mathrm{N}$ : The biology and therapeutic potential of interleukin 27. J Mol Med 2007, 85:661-672.

5. Kastelein RA, Hunter CA, Cua DJ: Discovery and biology of IL-23 and IL-27: related but functionally distinct regulators of inflammation. Annu Rev Immunol 2007, 25:221-242.

6. Heinrich PC, Behrmann I, Haan S, Hermanns HM, Muller-Newen G, Schaper F: Principles of interleukin (IL)-6-type cytokine signalling and its regulation. Biochem J 2003, 374:1-20.

7. Bender H, Wiesinger MY, Nordhoff C, Schoenherr C, Haan C, Ludwig S, Weiskirchen R, Kato N, Heinrich PC, Haan S: Interleukin-27 displays interferon-gamma-like functions in human hepatoma cells and hepatocytes. Hepatology 2009, 50:585-591.

8. Zhu C, Zhang R, Liu L, Rasool ST, Mu Y, Sun W, Hao Q, Liu F, Zhu Y, Wu J: Hepatitis B virus enhances interleukin-27 expression both in vivo and in vitro. Clin Immunol 2009, 131:92-97.

9. Xu L, Hui AY, Albanis E, Arthur MJ, O'Byrne SM, Blaner WS, Mukherjee P, Friedman SL, Eng FJ: Human hepatic stellate cell lines, LX-1 and LX-2: new tools for analysis of hepatic fibrosis. Gut 2005, 54:142-151.

10. Haan S, Keller JF, Behrmann I, Heinrich PC, Haan C: Multiple reasons for an inefficient STAT1 response upon IL-6-type cytokine stimulation. Cell Signal 2005, 17:1542-1550.

11. Sadler AJ, Williams BR: Interferon-inducible antiviral effectors. Nat Rev Immunol 2008, 8:559-568

12. Jeong WI, Park O, Radaeva S, Gao B: STAT1 inhibits liver fibrosis in mice by inhibiting stellate cell proliferation and stimulating NK cell cytotoxicity. Hepatology 2006, 44:1441-1451.

13. Weng H, Mertens PR, Gressner AM, Dooley S: IFN-gamma abrogates profibrogenic TGF-beta signaling in liver by targeting expression of inhibitory and receptor Smads. J Hepatol 2007, 46:295-303.

14. Yamanaka A, Hamano S, Miyazaki Y, Ishii K, Takeda A, Mak TW, Himeno K, Yoshimura A, Yoshida H: Hyperproduction of proinflammatory cytokines by WSX-1-deficient NKT cells in concanavalin A-induced hepatitis. J Immunol 2004, 172:3590-3596.

15. Schmidt C, Giese T, Ludwig B, Mueller-Molaian I, Marth T, Zeuzem S, Meuer SC, Stallmach A: Expression of interleukin-12-related cytokine transcripts in inflammatory bowel disease: elevated interleukin-23p19 and interleukin-27p28 in Crohn's disease but not in ulcerative colitis. Inflamm Bowel Dis 2005, 11:16-23.

16. Hisada M, Kamiya S, Fujita K, Belladonna ML, Aoki T, Koyanagi Y, Mizuguchi J, Yoshimoto T: Potent antitumor activity of interleukin-27. Cancer Res 2004, 64:1152-1156.

17. Chiyo M, Shimozato O, Yu L, Kawamura K, lizasa T, Fujisawa T, Tagawa M: Expression of IL-27 in murine carcinoma cells produces antitumor effects and induces protective immunity in inoculated host animals. Int $\mathrm{J}$ Cancer 2005, 115:437-442.

18. Hu P, Hu HD, Chen M, Peng ML, Tang L, Tang KF, Matsui M, Belladonna ML, Yoshimoto T, Zhang DZ, et al: Expression of interleukins-23 and 27 leads to successful gene therapy of hepatocellular carcinoma. Mol Immunol 2009, 46:1654-1662.

19. Wegenka UM, Buschmann J, Lütticken C, Heinrich PC, Horn F: Acute-phase response factor, a nuclear factor binding to acute-phase response elements, is rapidly activated by interleukin- 6 at the posttranslational level. Mol Cell Biol 1993, 13:276-288.

20. Heinrich PC, Behrmann I, Müller-Newen G, Schaper F, Graeve L: Interleukin6-type cytokine signalling through the gp130/Jak/STAT pathway. Biochem J 1998, 334:297-314.

21. Michalopoulos GK, DeFrances MC: Liver regeneration. Science 1997, 276:60-66.

22. Mahboubi K, Pober JS: Activation of signal transducer and activator of transcription 1 (STAT1) is not sufficient for the induction of STAT1dependent genes in endothelial cells. Comparison of interferon-gamma and oncostatin M. J Biol Chem 2002, 277:8012-8021.

23. Costa-Pereira AP, Tininini S, Strobl B, Alonzi T, Schlaak JF, Is'harc H Gesualdo I, Newman SJ, Kerr IM, Poli V: Mutational switch of an IL-6 response to an interferon-gamma-like response. Proc Natl Acad Sci USA 2002, 99:8043-8047.

24. Takeda A, Hamano S, Yamanaka A, Hanada T, Ishibashi T, Mak TW, Yoshimura A, Yoshida H: Cutting edge: role of IL-27/WSX-1 signaling for induction of T-bet through activation of STAT1 during initial Th1 commitment. J Immunol 2003, 170:4886-4890.

25. Lucas S, Ghilardi N, Li J, de Sauvage FJ: IL-27 regulates IL-12 responsiveness of naive CD4+ T cells through Stat1-dependent and -independent mechanisms. Proc Natl Acad Sci USA 2003, 100:15047-15052.

26. Kamiya S, Owaki T, Morishima N, Fukai F, Mizuguchi J, Yoshimoto T: An indispensable role for STAT1 in IL-27-induced T-bet expression but not proliferation of naive CD4+ T cells. J Immunol 2004, 173:3871-3877.

27. Imamichi T, Yang J, Huang DW, Brann TW, Fullmer BA, Adelsberger JW, Lempicki RA, Baseler MW, Lane HC: IL-27, a novel anti-HIV cytokine, activates multiple interferon-inducible genes in macrophages. Aids 2008, 22:39-45.

28. Yoshimura T, Takeda A, Hamano S, Miyazaki Y, Kinjyo I, Ishibashi T, Yoshimura A, Yoshida H: Two-sided roles of IL-27: induction of Th1 differentiation on naive CD4+ T cells versus suppression of proinflammatory cytokine production including IL-23-induced IL-17 on activated CD4+ T cells partially through STAT3-dependent mechanism. J Immunol 2006, 177:5377-5385.

29. Greenlund AC, Farrar MA, Viviano BL, Schreiber RD: Ligand-induced IFN gamma receptor tyrosine phosphorylation couples the receptor to its signal transduction system (p91). Embo J 1994, 13:1591-1600.

30. Gerhartz C, Heesel B, Sasse J, Hemmann U, Landgraf C, SchneiderMergener J, Horn F, Heinrich PC, Graeve L: Differential activation of acute phase response factor/STAT3 and STAT1 via the cytoplasmic domain of the interleukin 6 signal transducer gp130. I. Definition of a novel phosphotyrosine motif mediating STAT1 activation. J Biol Chem 1996, 271:12991-12998.

31. Lehmann U, Sommer U, Smyczek T, Hortner M, Frisch W, Volkmer-Engert R, Heinrich PC, Schaper F, Haan S: Determinants governing the potency of STAT3 activation via the individual STAT3-recruiting motifs of gp130. Cell Signal 2006, 18:40-49.

32. Fakruddin JM, Lempicki RA, Gorelick RJ, Yang J, Adelsberger JW, GarciaPineres AJ, Pinto LA, Lane HC, Imamichi T: Noninfectious papilloma viruslike particles inhibit HIV-1 replication: implications for immune control of HIV-1 infection by IL-27. Blood 2007, 109:1841-1849.

33. Zeuzem S: Interferon-based therapy for chronic hepatitis C: current and future perspectives. Nat Clin Pract Gastroenterol Hepatol 2008, 5:610-622.

34. Chen Y, Jiang G, Yang HR, Gu X, Wang L, Hsieh CC, Chou HS, Fung J. Qian S, Lu L: Distinct response of liver myeloid dendritic cells to endotoxin is mediated by IL-27. J Hepatol 2009, 51:510-519.

35. Ghosh AK, Yuan W, Mori Y, Chen S, Varga J: Antagonistic regulation of type I collagen gene expression by interferon-gamma and transforming growth factor-beta. Integration at the level of p300/CBP transcriptional coactivators. J Biol Chem 2001, 276:11041-11048.

36. Weiskirchen R, Gressner AM: Isolation and culture of hepatic stellate cells. Methods Mol Med 2005, 117:99-113.

37. Dennler S, Itoh S, Vivien D, ten Dijke P, Huet S, Gauthier JM: Direct binding of Smad3 and Smad4 to critical TGF beta-inducible elements in the promoter of human plasminogen activator inhibitor-type 1 gene. EMBO $J$ 1998, 17:3091-3100. 
38. Haan S, Margue C, Engrand A, Rolvering C, Schmitz-Van de Leur H, Heinrich PC, Behrmann I, Haan C: Dual Role of the Jak1 FERM and Kinase Domains in Cytokine Receptor Binding and in Stimulation-Dependent Jak Activation. J Immunol 2008, 180:998-1007.

39. Pfaffl MW, Horgan GW, Dempfle L: Relative expression software tool (REST) for group-wise comparison and statistical analysis of relative expression results in real-time PCR. Nucleic Acids Res 2002, 30:e36.

doi:10.1186/1478-811X-8-19

Cite this article as: Schoenherr et al:: Interleukin-27 acts on hepatic stellate cells and induces signal transducer and activator of transcription 1-dependent responses. Cell Communication and Signaling 2010 8:19.

Submit your next manuscript to BioMed Central and take full advantage of:

- Convenient online submission

- Thorough peer review

- No space constraints or color figure charges

- Immediate publication on acceptance

- Inclusion in PubMed, CAS, Scopus and Google Scholar

- Research which is freely available for redistribution

Submit your manuscript at www.biomedcentral.com/submit
C Biomed Central 